\title{
Ảnh hưởng của xâm nhập lạnh sâu đến mưa ở Việt Nam
}

\author{
Trần Tân Tiến* \\ Khoa Khi tuợng Thủy văn và Hải dương học, Truòng Đại học Khoa học Tụ nhiên, \\ Đại học Quốc gia Hà Nội, 334 Nguyễn Trãi, Thanh Xuân, Hà Nội, Việt Nam \\ Nhận ngày 08 tháng 8 năm 2016 \\ Chỉnh sửa ngày 26 tháng 8 năm 2016; Chấp nhận đăng ngày 16 tháng 12 năm 2016
}

\begin{abstract}
Tóm tắt: Sử dụng mô hình RAMS mô phỏng các đợt xâm nhập lạnh sâu xuống Việt Nam và dự báo lượng mưa trong các đợt lạnh này. Không khí lạnh hoạt động độc lập và không tạo ra xoáy ở Borneo gây ra mưa lớn các tỉnh phía Bắc, vùng mưa lan rộng đến khu vực ven biển Trung Bộ, Nam Bộ hoàn toàn không có mưa. Trường hợp không khí lạnh đã xuống rất sâu, nhưng đến ngày thứ 2 của đợt mới xuất hiện xoáy Borneo, đã gây ra diện mưa lớn cho toàn khu vực Việt Nam nhưng lượng mưa thu được lại tương đối thấp, chỉ từ $10-20 \mathrm{~mm} / 48 \mathrm{~h}$. Khi xoáy Borneo đã hình thành và duy trì liên tục trong suốt đợt xâm nhập lạnh, vùng mưa mô phỏng bao phủ rộng lớn các tỉnh phía Bắc Trung Bộ, Trung Trung Bộ và $\mathrm{c} a ̉$ khu vực Nam Bộ . Tùy thuộc vào cường độ hoạt động của xoáy Borneo mà lượng mưa mô phỏng tại vùng tâm mưa có thể đạt từ $50-160 \mathrm{~mm} / 48 \mathrm{~h}$.
\end{abstract}

Tù̀ khóa: Xâm nhập lạnh, xoáy Borneo, lượng mưa.

\section{Mở đầu}

Mưa lớn là hệ quả của một số loại hình thời tiết đặc biệt như xâm nhập không khí lạnh, bão, áp thấp nhiệt đới hay dải hội tụ nhiệt đới... Đặc biệt khi có sự kết hợp của chúng sẽ càng nguy hiểm hơn gây nên mưa, mưa vừa đến mưa to, trong một thời gian dài trên một phạm vi rộng. Bài báo này trình bày những nghiên cứu về ảnh hưởng của xâm nhập lạnh sâu đến mưa ở Việt Nam.

Xâm nhập lạnh là khối không khí rất lạnh từ lục địa Châu Á di chuyển xuống nước ta . Khối không khí lạnh này có nguồn gốc cực đới , tràn qua lục địa C hâu Á dưới dạng front lạnh . Ở nước ta không khí lạnh thường thấy từ tháng 9 -

\footnotetext{
ĐT.: 84-4-38584945

Email: tientt@vnu.edu.vn
}

10 đến tháng 5 - 6 năm sau, nhưng mạnh nhất vào các tháng chính đông . ảnh hưởng trực tiếp là khu vực phía Bắc, từ đèo Ngang trở ra, ít khi đến Nam Trung Bộ. Bên cạnh đó vẫn tồn tại những đợt không khí lạnh có cường độ cực mạnh, xâm nhập sâu xuống xích đạo gây ra mưa lớn diện rộng cho khu vực Việt Nam. Xâm nhập sâu của không khí lạnh thường xẩy ra liên quan đến xuất hiện xoáy Borneo. Xoáy Borneo, được coi như là gió mùa xáo trộn với quy mô synop mực thấp thịnh hành trong rãnh gió mùa, liên tục hình thành ngoài khơi bờ biển của đảo Borneo trong giai đoạn gió mùa mùa đông Bắc Bán Cầu từ giữa tháng 11 đến tháng 2 năm sau. Vị trí trung bình của tâm xoáy nằm ngoài khơi bờ biển phía Tây đảo Borneo. Tuy nhiên có một số ít trường hợp đã gi lại được xoáy Borneo dịch chuyển xuống sâu, vượt xích đạo và quay theo chiều thuận kim đồng hồ ở Nam Bán Cầu. 
Xoáy Borneo thường hoạt động đơn lẻ trên biển, nhưng vẫn có những trường hợp xảy ra xoáy kép, tức là xuất hiện hai xoáy cùng hoạt động gần nhau trong cùng một thời điểm [1].

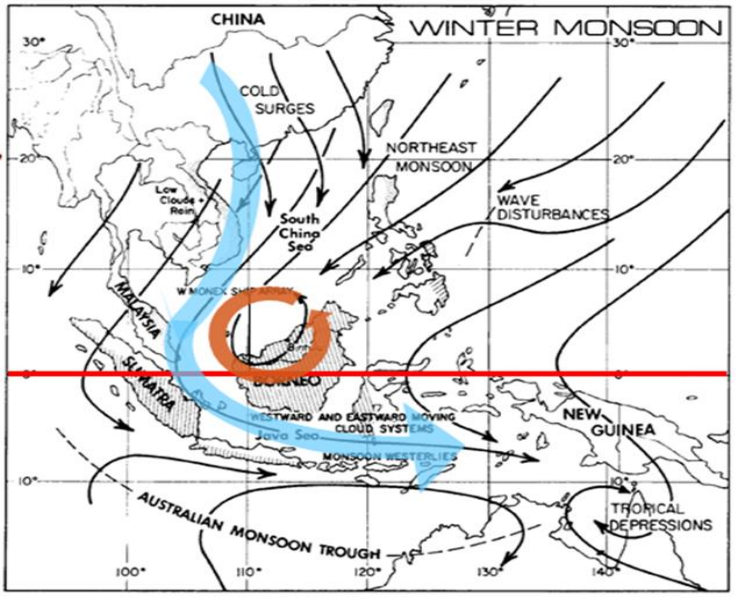

Hình 1. Sự kết hợp của không khí lạnh và xoáy Borneo trong giai đoạn gió mùa mùa đông.

Sự hiện diện của các xoáy trong khu vực này kết hợp với sự hoạt động mạnh mẽ của gió mùa mùa đông dẫn đến các hiện tượng thời tiết nguy hiểm như mưa lớn, lũ lụt, bão nhiệt đới, cụ thể là TS Greg (1996) và Typhoon Vamei (2001). Đây được coi là hiện tượng bất thường trên khu vực này [2]. Mưa lớn do không khí lạnh đã là hiện tượng nguy hiểm nhưng mưa lớn còn mạnh hơn, kéo dài hơn do tác động đới gió đông mạnh trên cao kết hợp với xoáy Borneo. Quá trình xảy ra mưa lớn không chỉ phụ thuộc vào cường độ không khí lạnh, xoáy Borneo mà còn phụ thuộc vào thời gian tác động của hai hệ thống trên [3]. Sự kết hợp giữa không khí lạnh và xoáy Borneo được biểu diễn trên hình 1 .

\section{Mô hình RAMS và các trường hợp mô phỏng}

RAMS (Regional Atmospheric Modeling System) là một mô hình khu vực hạn chế được xây dựng và phát triển tại trường Đại học tổng hợp Colorado -Mỹ. Mô hình thường được sử dụng để mô phỏng các hiện tượng khí quyển qui mô vừa $(2-2000 \mathrm{~km})$ từ dự báo thời tiết nghiệp vụ đến các ứng dụng để mô phỏng, quản lý chất lượng môi trường không khí. Các tham số của mô hình được chọn như trong công trình [4].

\subsection{Miền dụ báo và cấu hình lưới}

Đã tiến hành thử nghiệm dự báo xâm nhập lạnh và mưa cho lãnh thổ Việt Nam $b$ ằng mô hình RAMS với 1 lưới với độ phân giải ngang $30 \mathrm{~km}$. Miền dự báo gồm $181 \times 181$ điểm lưới theo phương ngang, tạo ra miền lưới tính có kích thước $5400 \times 5400 \mathrm{~km}^{2}$. Tâm miền tính tại $10^{\circ} \mathrm{N}, 115^{\circ} \mathrm{E}$. Miền tính này bao phủ toàn bộ lãnh thổ Việt Nam, một phần lục địa Trung Quốc và toàn bộ khu vực đảo Borneo . Biên giới phía Nam của miền tính ở vào khoảng $15^{\circ} \mathrm{S}$ (hình 2).

\subsection{Số liệu thủ nghiệm}

Đã chọn 2 đợt xâm nhập lạnh vào các ngày $10 / 11 / 2014$ và $25 / 01 / 2016$. Đây là những đợt không khí lạnh tràn về cùng kết hợp với xoáy Borneo gây ra mưa lớn cho cả những tỉnh phía Nam của nước ta. Danh sách các đợt mưa và đặc điểm hoàn lưu được đưa ra trong Bảng 1 .

Các đợt không khí lạnh tràn về xếp thứ tự theo mức độ tiến sâu về phía nam tăng dần, ảnh hưởng của nó đến thời tiết nam bộ cũng tăng theo. Số liệu sử dụng để tính toán và đánh giá lết quả dự báo là số liệu GFS và số liệu mưa ở các trạm ở Việt nam trong các đợt kể trên.

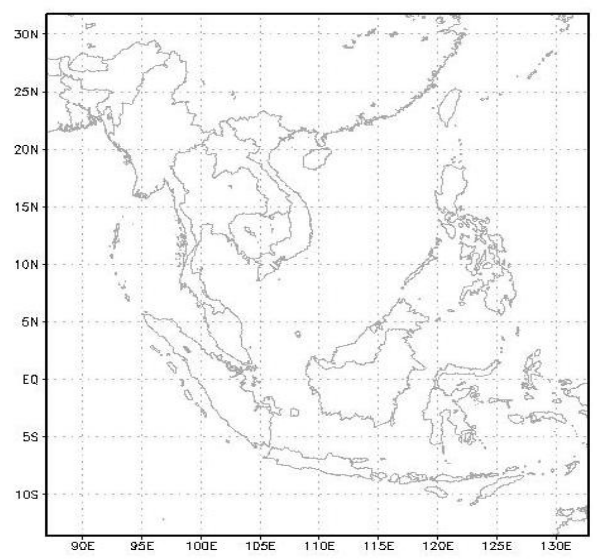

Hình 2. Miền tính của mô hình RAMS. 
Bảng 1. Các đợt không khí lạnh và đặc điểm hoàn lưu

\begin{tabular}{lll}
\hline TT $\quad$ Đợt không khí lạnh & Đặc điểm của hoàn lưu \\
\hline 1 & $25 / 01-28 / 01 / 2016$ & $\begin{array}{l}\text { Hoàn toàn không có sự xuất hiện của vùng thấp phía Tây } \\
\text { đảo Borneo trong suốt quá trình không khí lạnh tràn về } \\
\text { nước ta. }\end{array}$ \\
& $\begin{array}{l}\text { Ngày thứ hai của đợt không khí lạnh bắt đầu có sự xuất } \\
\text { hiện của xoáy Borneo. }\end{array}$ \\
& $\begin{array}{l}\text { Ngay từ ngày đầu của đợt không khí lạnh đã có sứ hoạt } \\
\text { động của xoáy Borneo và được duy trì xuyên suốt cả đợt. }\end{array}$ \\
\hline
\end{tabular}

\section{Kết quả dự báo}

Mô hình đã sử dụng số liệu $00 \mathrm{z}$ ngày đầu của các đợt xâm nhập lạnh làm điều kiện ban đầu dự báo cho 3 ngày tiếp theo. Hình 3 biểu diễn dường dòng mực $850 \mathrm{hpa}$ dự báo cho $00 \mathrm{z}$ ngày 26/01/2016, 12/11/2014 và 18/12/2014. Các hình từ 4 đến 6 biểu diễn lượng mưa tích lũy 24 và 48 giờ dự báo được tại các trạm khí tượng của Việt nan. Sai số tuyệt đối của dự báo thể hiện trên các bảng 3-5. Từ các bảng này cho thấy kết quả dự báo được ở đây khá phù hợp với lượng mưa đo được ở các trạm.

Từ bản đồ đường dòng hình $3 \mathrm{a}$ nhận thấy trường hợp thử nghiệm này hoàn toàn không có sự xuất hiện của xoáy Borneo, tại khu vực phía Nam không ghi nhận thấy mưa (Hình 4). Trong suốt đợt xâm nhập không khí lạnh này Việt Nam bi khối cao lạnh lục địa khống chế với cường độ rất mạnh, đặc biệt là khu vực Bắc Bộ. Sự tồn tại liên tục và kéo dài này là nguyên nhân chủ chốt gây ra đợt rét đậm rét hại và mưa lớn xảy ra tại Hà Nội và các hu vực khác ở miền Bắc Việt Nam

Kết quả dự báo 24 giờ cho thấy lượng mưa khá lớn ở Bắc Bộ tại trạm Thanh Hóa là 48.2 mm. Là trường hợp không khí lạnh hoạt động độc lập, không có sự kết hợp với bất kỳ hình thế synop nào khác, toàn bộ khu vực phía Bắc trở xuống đến ven biển Nam Trung Bộ đã xảy ra mưa vừa, có nơi mưa to. Lượng mưa giảm dần từ Bắc vào Nam. Tâm mưa cực đại ghi nhận được tại Thanh Hóa. Một tâm mưa thứ hai với lượng mưa nhỏ hơn là $40 \mathrm{~mm}$ bao trùm khu vực Điện Biên. Toàn bộ Hà Nội và cá c khu vực lân cận nằm trong vùng mưa lớn. Ở miền Nam, mô hình bắt được lượng mưa rất nhỏ cho các trạm Tân Sơn Nhất, Cần Thơ và Cà Mau. Trên thực tế các trạm này không mưa. Lượng mưa tích lũy $48 \mathrm{~h}$ tăng mạnh tại các trạm khu vực phía Bắc, các trạm từ Huế trở vào có sự thay đổi không nhiều của lượng mưa tích lũy $24 \mathrm{~h}$ và $48 \mathrm{~h}$ (hình 4 ).

Đợt không khí lạnh ngày 10 - 13/11/2014 là đợt KKL rất mạnh tràn xuống nước ta. Sự xuất hiện của vùng thấp phía Tây đảo Borneo được mô hình dự báo trên mực 850mb ( Hình 3b ). Mưa bắt đầu từ phía bắc sau lan dần về phía nam theo quá trình tác động của KKL. Diện mưa phủ rộng toàn lãnh thổ Việt Nam tuy nhiên lượng mưa không lớn. Kết quả mô hình dự báo cũng cho ta thây được lượng mưa trong đợt này từ 2 $10 \mathrm{~mm} / 24 \mathrm{~h}$ cho toàn khu vực Việt Nam. Vùng mưa trải đều. Tâm mưa trải dọc bở biển miền Trung. Điểm mưa lớn nhất ghi nhận được tại trạm Quảng Ngãi là $9.8 \mathrm{~mm}$. Tâm mưa thứ hai nằm ở khu vực Nha Trang. Lượng mưa tích lũy $48 \mathrm{~h}$ đã bao phủ lên toàn Việt Nam và không lớn từ 10 đến $20 \mathrm{~mm}$ (hình 5 ). Dựa trên số liệu mưa thực đo tại các trạm cho thấy, các trạm Nam Bộ mồ hình bắt mưa tốt hơn các trạm ở Bác Bộ (bảng 3).

Đợt xâm nhập lạnh thứ 3 từ 15 đến $18 / 12 / 2014$. Thời điểm $07 \mathrm{~h}$ ngày $17 / 12$ toàn bộ miền Bắc cho đến Trung Trung Bộ đã hoàn toàn chịu sự chi phối của áp cao Siberia với cường độ khá mạnh cho đến ngày 18/12. Bên cạnh đó, vùng áp thấp tại khu vực đảo Borneo đã hình thành ngay từ ngày đầu tiên của đợt lạnh và tồn tại suốt cả quá trình, cho đến ngày $18 / 12$ thì vùng thấp này đã bị đẩy sang phía Tây (hình $3 \mathrm{c}$ ). 


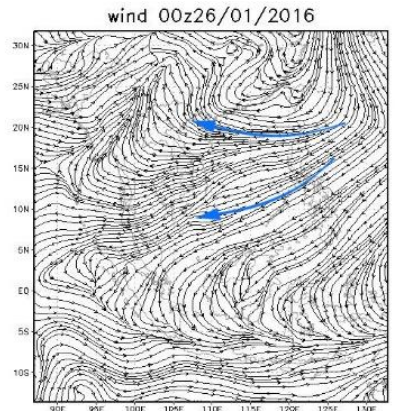

a)

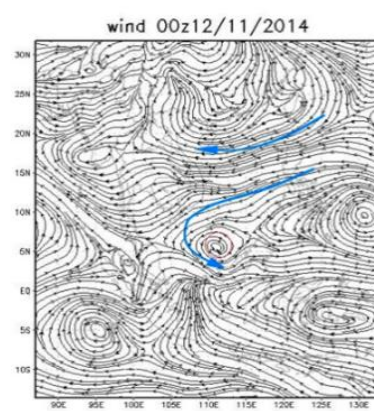

b)

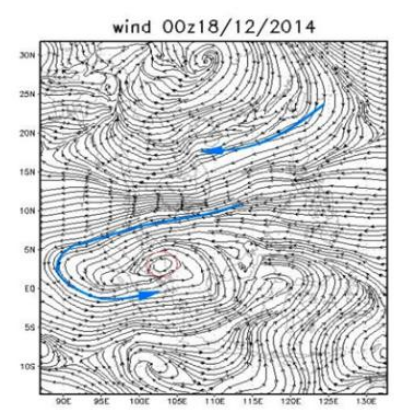

c)

Hình 3. Trường đường dòng mực 850 hpa dự báo cho $00 \mathrm{z}$ ngày 26/1/2016 (a), 12/11/2014 (b) và 18/12/2014 (c).

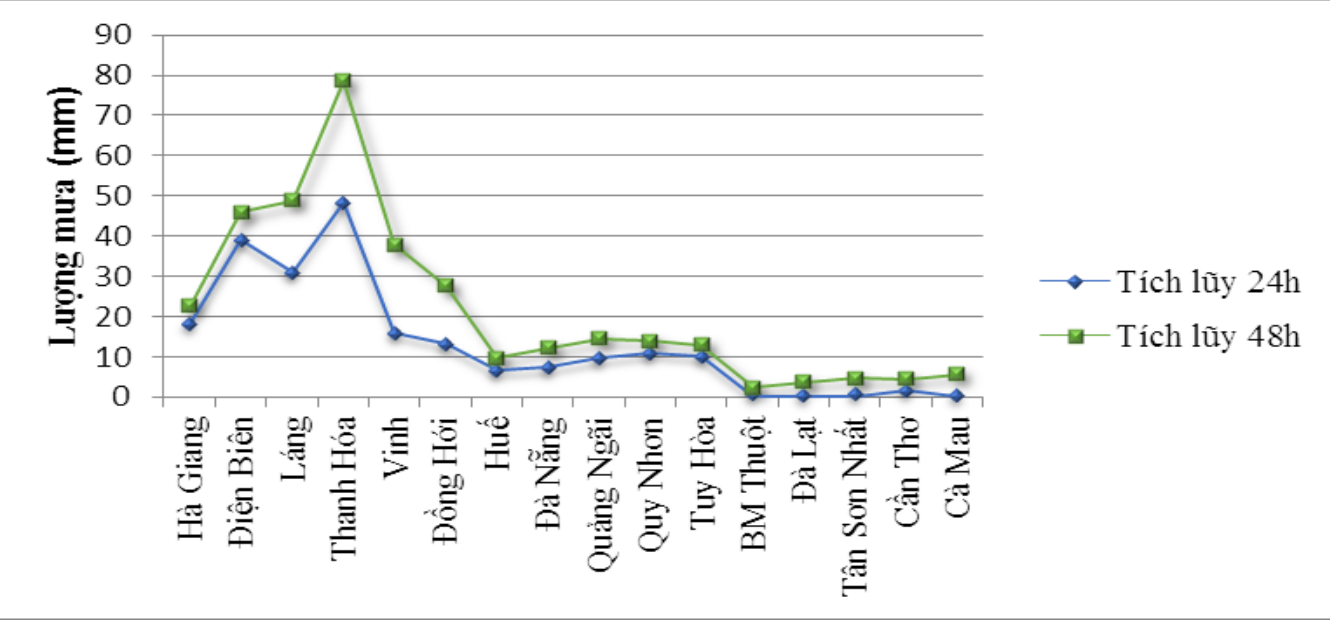

Hình 4. Lượng mưa mô hình các trạm synop tích lũy 24h và 48h ngày 25/01/2016.

Bảng 2. Sai số tuyệt đối giữa lượng mưa mô hình và thực tế hạn dự báo 24h và 48h ngày 25/01/2016

\begin{tabular}{|c|c|c|c|c|c|}
\hline Trạm Hạn dự báo & $24 \mathrm{~h}$ & $48 \mathrm{~h}$ & Trạm Hạn dự báo & $24 \mathrm{~h}$ & $48 \mathrm{~h}$ \\
\hline Hà Giang & 4.6 & 8.6 & Quảng Ngãi & 18.5 & 13.5 \\
\hline Điện Biên & 1.5 & 2.4 & Quy Nhơn & 2.4 & 5 \\
\hline Láng & 7.3 & 6.5 & Tuy Hòa & 6.7 & 6 \\
\hline Thanh Hóa & 16.4 & 8.6 & BM Thuột & 0.5 & 2.4 \\
\hline Vinh & 5.6 & 10.5 & Đà Lạt & 0.2 & 3.9 \\
\hline Đồng Hới & 9.4 & 23.9 & Tân Sơn Nhất & 0.8 & 4.7 \\
\hline Huế & 3 & 1.1 & Cần Thơ & 1.5 & 4.5 \\
\hline Đà Nẵng & 3.1 & 8.1 & Cà Mau & 0.4 & 5.8 \\
\hline
\end{tabular}




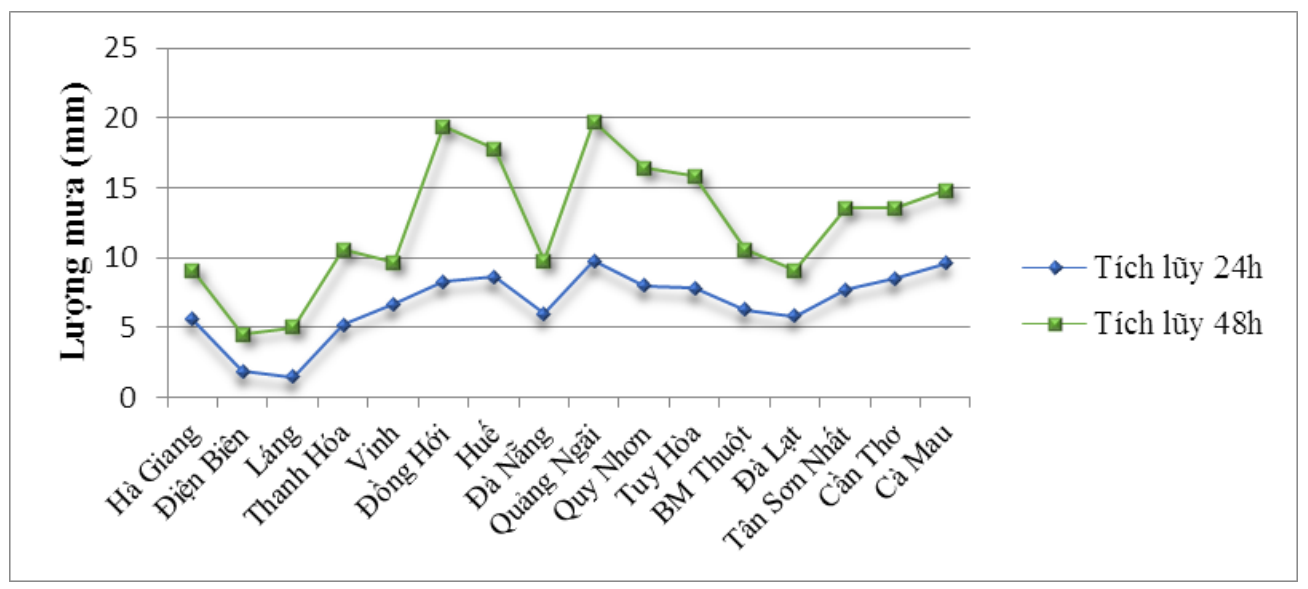

Hình 5. Lượng mưa mô hình các trạm synop hạn 24h và 48h ngày 10/11/2016.

Bảng 3. Sai số tuyệt đối giữa lượng mưa mô hình và thực tế hạn dự báo 24h và 48h ngày 10/11/2014

\begin{tabular}{|c|c|c|c|c|c|}
\hline Trạm Hạn dự báo & $24 \mathrm{~h}$ & $48 \mathrm{~h}$ & Trạm Hạn dự báo & $24 \mathrm{~h}$ & $48 \mathrm{~h}$ \\
\hline Hà Giang & 5 & 6.4 & Quảng Ngãi & 2.8 & 12.7 \\
\hline Điện Biên & 1.9 & 4.5 & Quy Nhơn & 1.1 & 9.5 \\
\hline Láng & 1.2 & 2.8 & Tuy Hòa & 7.1 & 9 \\
\hline Thanh Hóa & 4.7 & 9.7 & BM Thuột & 5.8 & 3.3 \\
\hline Vinh & 5.9 & 3.6 & Đà Lạt & 4.4 & 6.8 \\
\hline Đồng Hới & 4.8 & 5 & Tân Sơn Nhất & 1.2 & 3 \\
\hline Huế & 5.1 & 2.1 & Cần Thơ & 4.2 & 5.8 \\
\hline Đà Nẵng & 1 & 4.7 & Cà Mau & 2.2 & 7.2 \\
\hline
\end{tabular}

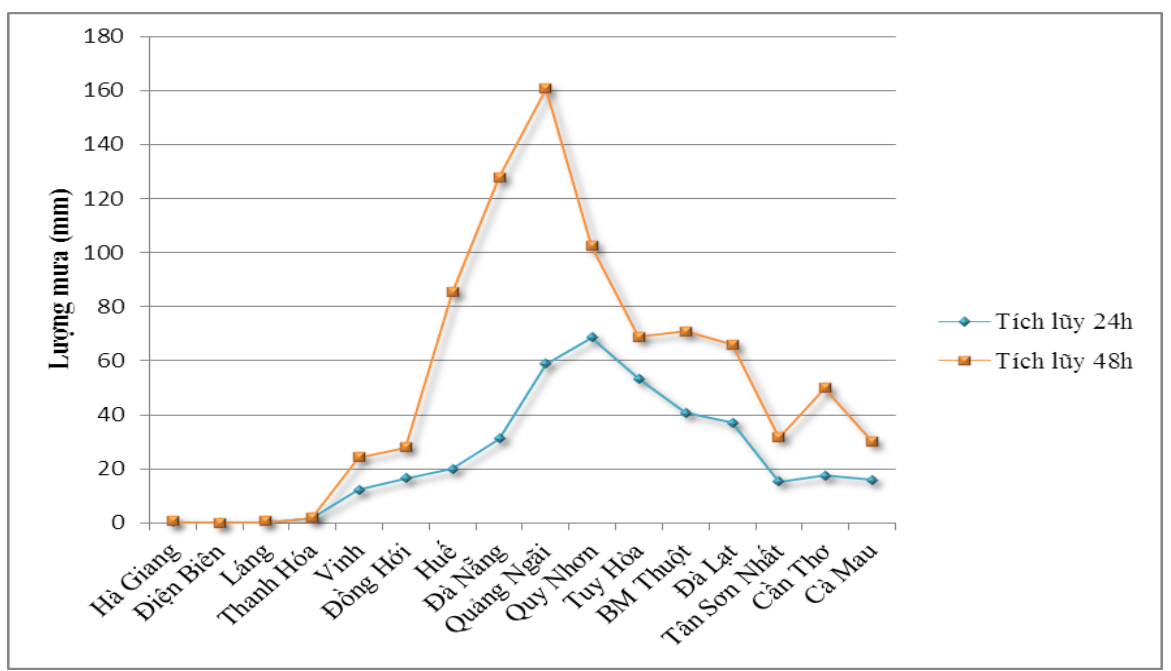

Hình 6. Lượng mưa mô hình các trạm synop hạn 24h và 48h ngày 15/12/2014. 
Bảng 4. Sai số tuyệt đối giữa lượng mưa mô hình và thực tế hạn dự báo 24 h và 48 h ngày 15/12/2014

\begin{tabular}{|c|c|c|c|c|c|}
\hline Trạm Hạn dự báo & $24 \mathrm{~h}$ & $48 \mathrm{~h}$ & Trạm Hạn dự báo & $24 \mathrm{~h}$ & $48 \mathrm{~h}$ \\
\hline Hà Giang & 0.5 & 0.7 & Quảng Ngãi & 27.8 & 56.4 \\
\hline Điện Biên & 0 & 0 & Quy Nhơn & 34 & 22 \\
\hline Láng & 0.8 & 0.9 & Tuy Hòa & 23.7 & 31.99 \\
\hline Thanh Hóa & 1.9 & 2 & BM Thuột & 33.6 & 55.2 \\
\hline Vinh & 11.8 & 23.8 & Đà Lạt & 21.7 & 50.6 \\
\hline Đồng Hới & 10.5 & 21.9 & Tân Sơn Nhất & 11.5 & 12.9 \\
\hline Huế & 8 & 29.4 & Cần Thơ & 5.5 & 25.3 \\
\hline Đà Nẵng & 24.1 & 86.9 & Cà Mau & 6.4 & 9.6 \\
\hline
\end{tabular}

Như vậy, với sự xâm nhập rất nhanh và cường độ mạnh của đợt không khí lạnh này đã gây ra mưa lớn cho khu vực miền Trung. Do sự kết hợp với xoáy Borneo nên đã gây ra mưa cho khu vực Nam Bộ 50mm/48 giờ (hình 6).

So với cường độ của 2 trường hợp thử nghiệm trên thì đợt không khí lạnh ngày $15 / 12$ đã gây ra lượng mưa tăng đột biến tại khu vực miền Trung. Tâm mưa trải dọc ven biển các tỉnh Nam Trung Bộ, kéo dài từ tỉnh Quảng Ngãi đến Khánh Hòa. Ngoài tâm mưa lớn nhất trên biển Đông với lượng từ $70-80 \mathrm{~mm}$ thì một trung tâm vùng mưa lớn thứ hai nằm ở Đắk Lắk với lượng mưa được dự báo đạt $70 \mathrm{~mm}$ trong 24 giờ. Kết quả mô hình dự báo cũng cho ta lượng mưa khá lớn tại trạm Quảng Ngãi là 58.9 mm, trạm Quy Nhơn là $68.5 \mathrm{~mm}$ và trạm Tuy Hòa là $53.3 \mathrm{~mm}$

Sau 24h, tâm mưa đã mở rộng và dịch chuyển sang phía Tây, bao trùm khu vực Đà Nẵng và Quảng Ngãi. Dựa trên số liệu mưa thực đo tại các trạm cho thấy trên thực tế tồn tại các tâm mưa lớn tại vị trí điểm trạm Quảng Ngãi. Lượng mưa tích lũy thực tế 48 giờ của Trạm Quảng Ngãi là 104,2 mm ( lượng mưa tích lũy mô hình bắt được lại là $160.6 \mathrm{~mm}$ ). Mô hình đã mô phỏng được xu thế mưa ở các trạm nhưng tâm mưa bị lệch về phía Tây so với thực tế. Các trạm phía Bắc gần như không có sự thay đổi mưa trong toàn đợt không khí lạnh.

\section{Kết luận}

1. Mô hình RAMS đã dự báo được sự hình thành và phát triển hoàn lưu tại các mực đặc biệt là mô phỏng được sự hình thành của xoáy Borneo và dòng gió Đông đến Đông Bắc hoạt động mạnh mẽ trên khu vực Đông Nam Á.

2. Áp dụng dự báo cho 4 đợt xâm nhập lạnh thử nghiệm cho thấy:

- Trong suốt đợt không khí lạnh hoạt động độc lập và không tạo ra xoáy ở Borneo khu vực Bắc Bộ chịu sự khống chế của áp cao đã gây ra mưa lớn các tỉnh phía Bắc. Vùng mưa lan rộng đến khu vực ven biển Trung Bộ. Nam Bộ hoàn toàn không có mưa.

- Trường hợp khi không khí lạnh đã xuống rất sâu, nhưng đến ngày thứ 2 của đợt mới xuất hiện xoáy Borneo, đã gây ra diện mưa lớn cho toàn khu vực Việt Nam, nhưng lượng mưa thu được lại tương đối thấp, chỉ từ 10 - 20 mm/48h.

- Khi xoáy Borneo đã hình thành và duy trì liên tục trong suốt đợt xâm nhập lạnh, nhận thấy mô hình nắm bắt khá chính xác diện mưa của những đợt mưa này, vùng mưa mô phỏng bao phủ rộng lớn các tỉnh phía Bắc Trung Bộ, Trung Trung Bộ và cả khu vực Nam Bộ . Tùy thuộc vào cường độ hoạt động của xoáy Borneo mà lượng mưa mô phỏng tại vùng tâm mưa có thể đạt từ $50-160 \mathrm{~mm} / 48 \mathrm{~h}$. 


\section{Tài liệu tham khảo}

[1] S. Koseki, T.-Y. Koh, and C.-K. Teo (2014), Borneo vortex and mesoscale convective rainfall.

[2] Shigeo Yoden (Kyoto U., Japan), Synoptic scale disturbances: Cross equatorial cold surge and Borneo vortex, International Collaboration on Numerical Model Studies of Cold Surge and Borneo Vortex in the Maritime Continent.
[3] Robert et al. (2011): The maritime continent (MC) monsoon.

[4] Trần Tân Tiến, Nguyễn Minh Trường, Công Thanh, Kiều Quốc Chánh (2004): Sử dụng mô hình RAMS mô phỏng đợt mưa lớn ở miền Trung tháng 9/2002, Tạp chí khoa học ĐHQGHN, KHTN \& CN tập XX (3PT), tr. 51 - 60.

\title{
Effect of Cold Surges on Rainfall in Vietnam
}

\author{
Tran Tan Tien \\ Faculty of Hydrology, Meteorology and Oceanography, VNU University of Science, \\ 334 Nguyen Trai, Thanh Xuan, Hanoi, Vietnam
}

\begin{abstract}
Using models RAMS to simulate cold surges into Vietnam and forecast rainfall in this cold spell. Cold surge operates independently and do not creates vortices in Borneo causes rain in the northern provinces, coastal areas of Central and absolutely no rain in Southern. When cold surge creates Borneo vortex, has caused heavy rainfall area for Vietnam but the whole region gained rainfall is relatively low, only $10-20 \mathrm{~mm} / 48 \mathrm{~h}$. When the Borneo vortex formed and maintained constant during the cold surge, simulated rain covered the vast north-central provinces, the Central and Southern region. Depending on the intensity of the vortex activity Borneo simulated rainfall at the heart of the rain could reach $50-160 \mathrm{~mm} / 48 \mathrm{~h}$.
\end{abstract}

Keywords: Cold surges, Borneo vortex, rainfall. 